\title{
Political Bazaar
}

\section{NOJAN ADAMI}

Academy of Art University
MARK MUECKENHEIM

Academy of Art University
In today's frequent power exchange between historically privileged groups and marginalized ones, the question of architecture's role in transcending its footprint is a critical one. The public life of streets, plazas and parks no longer allows for the friction of competing ideas to interface, replaced by virtue space, vast urban place, and policing. This project proposes a series of public spaces, a political bazaar, which occupies San Francisco's Civic Plaza. Overlapping activities are arranged as an urban corridor capable of constructing a dialogue that extends well beyond the politics of this particular city and place.

This speculative proposal for an underground market, and redefined open plaza above, establishes a new active street culture for the San Francisco civic center. Re-envisioning the urban axis as a potential zone of constant friction and high rates of retail turnover rejects models of urban permanence in favor of research that shows higher political tolerance in heterogeneous and dynamic spaces and places. It also is an urban proposition that engages the city in non-traditional ways, replacing visibility and openness with instruments of invisibility, darkness, enclosure and density. Right beneath the monumentality of Civic Plaza, a place that is increasingly devoid of public debate despite the diversity of socioeconomic groups in the Bay Area, the political bazaar makes its presence known in indirect ways. It slowly entices the public to enter underneath the plaza into a chaotic public life of debate disguised through the political act of shopping.

A below-grade reinvention of the of the historic bazaar typology connects high-density markets with civic life. Further and refined typological revisions also recur at the level of each individual market booth, ensuring a continuous and constant interplay of architectural, spatial, cultural and programmatic forces. Friction is choreographed to combat urban numbness as a distinctly political act of architecture, one that reverberates across the ever-homogenized urban plateau of the contemporary U.S. 


\section{Political Bazaar}

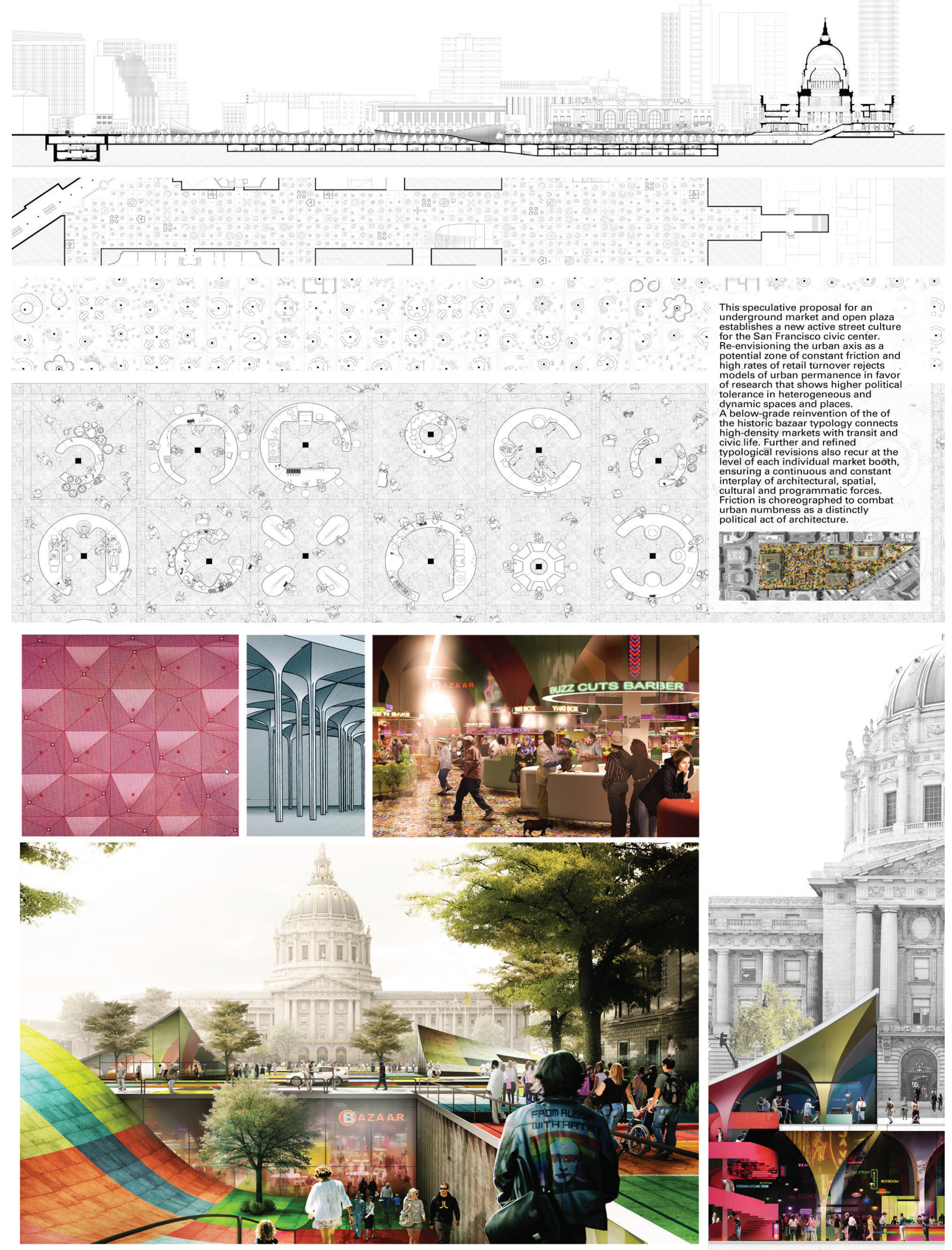

